Contents List available at RAZI Publishing

\title{
ENVIRONMENTAL CONTROL IN PETROLEUM OPERATIONS
}

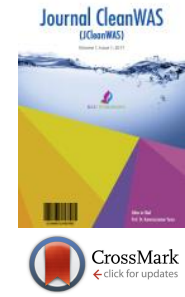

\author{
Mehdi Foroozanfar
}

\section{PhD Candidate in Petroleum Engineering, Department of Petroleum Engineering, Kish International Campus University of Tehran. *Corresponding author email: m.foroozanfar@ut.ac.ir}

This is an open access article distributed under the Creative Commons Attribution License, which permits unrestricted use, distribution, and reproduction in any medium, provided the original work is properly cited

\section{ARTICLE DETAILS}

\section{Article History:}

Received 7 July 2017

Accepted 7 October 2017

Available online 5 November 2017

Keywords:

Petroleum

Environmental conservation,

Hydrocarbon, contaminate

\section{ABSTRACT}

With the ascent of the environmental conservation movement, the petroleum industry has placed greater affirmation on minimizing the environmental impact of its operation. Improved environmental protection needs better education and training of industry personnel. The activities of finding and producing petroleum, however, can impact the environment, and the greatest impact arises from the release of waste into the environment in concentration that are not naturally found. These wastes include hydrocarbons, solids contaminated with hydrocarbons, water contaminated with a variety of dissolved and suspended solids and a wide variety of chemicals. The most significant steps in reducing adverse environmental influence are for the industry to take a proactive approach to managing operations and become educated about those activities that can potentially damage the environment. The proactive approach includes adopting an attitude of environmental responsibility not just to comply with regulations but to actually protect the environment while doing business. Petroleum operations requires a conception of assembled issues facing the upstream petroleum industry. These issues pertain to operations that generate wastes, treatment methods to reduce their volume and/or toxicity. In this article the importance of auditing in all processes of production and drilling in petroleum industry has been shown.

\section{INTRODUCTION}

With The upstream petroleum industry, which include all exploration and production processes, provide urgent petroleum outcomes that are used for transportation fuels, electrical power generation, space heating, medicine and petrochemicals. The proceedings of finding and producing petroleum, however, can impact the environment, and greatest impact arises from release of wastes into the environment in concentrations that are not naturally found. These wastes include hydrocarbons, solid contaminated with hydrocarbons, water contaminated with a diversity of dissolved and suspended solids, and wide variety of chemicals. While some of these wastes can have considerable adverse effects on the environment, some have little impact, and others are actually beneficial. Adverse impact can be minimized or eliminated through the implementation of proper waste management.

\subsection{Origin of Wastes}

Wastes are produced from diversity of activities related with petroleum production. These wastes fall into general classes of produced water, drilling wastes, and associated wastes. Produced water virtually always contains impurities, and if present in sufficient concentrations, these impurities can adversely impact the environment. These impurities include dissolved solid (primarily salt and heavy metals), suspended and dissolved organic materials, formation solids, hydrogen sulfide, and carbon dioxide, and have a deficiency of oxygen [1]. Produced water may also contain low level of naturally occurring radioactive materials [2]

Drilling wastes include formation cutting and drilling fluids. Water-based drilling fluids may involve viscosity control agents like clays, density control agents like barium sulfate. Oil-based drilling fluids also contain a base hydrocarbon and chemicals to maintain its water in oil emulsion. The most commonly used base hydrocarbon is diesel, followed by less toxic mineral and synthetic oils. Drilling fluids typically contain heavy metals like barium, chromium, cadmium, mercury and lead. These metals can enter the system from materials added to fluid or from naturally occurring minerals in formation being drilled.

\subsection{Environmental Impact of Wastes}

The primitive measure of the environmental impact of petroleum wastes is their toxicity to exposed organisms. The toxicity of a substance is most commonly reported as its concentration in water that results in the death of half of the exposed organism within a given length of time. Exposure times for toxicity tests are typically 96 hours. The concentration that is lethal to half of the exposed population during the test is called $L C_{50}$. High value of $L C_{50}$ mean that high concentration of the substance is needed for lethal effects to be observed, and this indicate a low toxicity.

The environmental impact of hydrocarbons in water varies considerably [3]. The toxicity of aromatic hydrocarbons is relatively high, while that of straight-chain paraffins is relatively low. $L C_{50}$ values for the most common aromatic hydrocarbons found in the petroleum industry (benzene, toluene and ethylbenzene) are on the order of $10 \mathrm{ppm}$. Hydrocarbon concentration of less than $1 \mathrm{mg} / \mathrm{L}$ in water have been shown to have a sublethal impacts on some marine organism. High molecular weight paraffins, on the other hand, are essentially nontoxic.

The high dissolved salt concentration of most produced water can also impact the environment. Typical dissolved salt concentration for produced water range between 50,000 and 150,000 ppm. By comparison, the salt concentration in seawater is about $35,000 \mathrm{ppm}$. Dissolved salt affects the ability of plants to adsorb water and nutrients from soil. It can also change the mechanical structure of the soil, which disrupts the transport of air and water to root systems. Water with dissolved salt concentration below about 2,500 $\mathrm{mg} / \mathrm{L}$ have minimal impact on most plants [4]. $L C_{50}$ value for dissolved salt concentration for freshwater organism are on order of 1,000 ppm [5].

The toxicity of drilling muds varies considerably, depending on their composition. Toxicities $\left(L C_{50}\right)$ of water-based muds containing small percentages of hydrocarbons can be a few thousands ppm. The $L C_{50}$ of polymer muds, however, can exceed one million, which means that fewer than $50 \%$ of a test species will have died during the test period.

The toxicity of heavy metal found in the upstream petroleum industry 
varies widely. The toxicity of many heavy metal lies in their interference with the action of enzymes, which limit or stops normal biochemical processes in cell. General effects include damage to liver, kidney, blood forming or nervous systems. With some metals, these effects may also include mutations or tumors.

\section{WASTE IMMIGRATION}

In most cases, the environmental impact of unleashed wastes would be minimal if the wastes settled at the location of release, unfortunately, most wastes immigrate from their release points to affect a wider area.

\subsection{Managing Wastes}

The most impressive procedure to minimize environmental impact from drilling and production operations is to expand and implement an effective waste management program. Waste management plans identify the materials and wastes at a particular site and list the best way to manage, treat and dispose of those wastes [6,7]. A waste management plan should also include an environmental audit to determine whether existing activities are in compliance with relevant regulations [8].

The effective management of each waste involve in a hierarchy of preferred steps. The first and usually important step is to minimize the amount of the waste that must be handled. The next step in effective waste management is to reuse or recycle wastes. If wastes contain valuable components, those components can be segregated or separated from the remainder of wastes stream and recovered for use. Wastes that cannot be reused or recycle must then be treated and disposed of.

\section{DRILLING AND PRODUCTION OPERATIONS}

In the upstream petroleum industry, there are two major operations that can potentially impact the environment: drilling and production. Both operations generate a significant volume of wastes. Environmentally responsible actions require an understanding of this wastes and how they are generated. From this understanding, improved operations that minimize or eliminate any adverse environmental impacts can be developed.

Drilling is the process in which a hole is made in the ground to allow subsurface hydrocarbons to flow to the surface. The wastes generated during drilling are the rock removed to make the hole (as cutting), the fluid used to lift the cuttings, and various material added to the fluid to change its properties to make it more suitable for use and to condition the hole.

Production is the process by which hydrocarbons flow to the surface to be treated and used. Water is often produced with hydrocarbons and contains a variety of contaminants. These contaminants include dissolved and suspended hydrocarbons and other organic materials, as well as dissolved and suspended solids. A variety of chemicals are also used during production to ensure efficient operations.

\subsection{Drilling}

The procedure of drilling oil and gas wells produce a variety of different kinds of wastes. Some of these wastes are natural byproducts of drilling through the earth for example drill cutting and some come from materials used to drill well for instance drilling fluid and its associated additives.

\subsubsection{Drilling Fluids}

Drilling fluid serve a number of intent in drilling a well. In most cases, however, the base fluid does not have proper physical or chemical properties to perform those purpose, and additive are needed to change its properties. Many of additive used in drilling fluid can be toxic and are now regulated. To comply with new regulations, many new additives have been formulated [9]. These new additives have a lower toxicity than those traditionally used, thus lowering the potential for environmental impact.

\subsubsection{Water-Based Drilling Fluids}

Water is the most generally used base for drilling fluids or muds. Because it does not have the physical and chemical properties needed to fulfill all of the requirement of a drilling mud, a number of additive are used to alter its properties. A typical elemental composition of common constituents of water-based drilling muds is given in table 1 .

Table 1: Elemental Composition of Drilling Constituents (mg/kg)

\begin{tabular}{|c|c|c|c|c|c|c|}
\hline Element & Water & Cutting & Barite & Clay & $\begin{array}{c}\text { Lignit } \\
\mathrm{e}\end{array}$ & Caustic \\
\hline
\end{tabular}

\begin{tabular}{|c|c|c|c|c|c|c|}
\hline $\begin{array}{c}\text { Aluminu } \\
\mathrm{m}\end{array}$ & 0.3 & 40,400 & 40,400 & $\begin{array}{c}88,60 \\
0\end{array}$ & 6,700 & 0.013 \\
\hline Arsenic & $\begin{array}{c}0.000 \\
5\end{array}$ & 3.9 & 34 & 3.9 & 10.1 & 0.039 \\
\hline Barium & 0.01 & 158 & $\begin{array}{c}590,00 \\
0\end{array}$ & 640 & 230 & 0.26 \\
\hline Calcium & 15 & $\begin{array}{c}240,00 \\
0\end{array}$ & 7,900 & 4,700 & $\begin{array}{c}16,10 \\
0\end{array}$ & 5,400 \\
\hline Cadmium & $\begin{array}{c}0.000 \\
1\end{array}$ & 0.08 & 6 & 0.5 & 0.2 & 0.0013 \\
\hline $\begin{array}{c}\text { Chromiu } \\
\text { m }\end{array}$ & 0.001 & 183 & 183 & 8.02 & 65.3 & $\begin{array}{c}0.0006 \\
6\end{array}$ \\
\hline Cobalt & $\begin{array}{c}0.000 \\
2\end{array}$ & 2.9 & 3.8 & 2.9 & 5 & $\begin{array}{c}0.0005 \\
3\end{array}$ \\
\hline Copper & 0.003 & 22 & 49 & 8.18 & 22.9 & 0.039 \\
\hline Iron & 0.5 & 21,900 & 12,950 & $\begin{array}{c}37,50 \\
0\end{array}$ & 7,220 & 0.04 \\
\hline
\end{tabular}

\subsubsection{Oil-Based Drilling Fluid}

Various organic fluids are also used as a base for drilling muds. In some cases, the properties of these oil-based muds are superior to those of water-based muds. Like water, however, these organic fluids do not have all of the proper physical and chemical properties needed to fulfill all of the requirements of drilling mud, so various additive are also used.

Oil-based muds are often preferred for high-temperature wells with temperature greater than about $300^{\circ} \mathrm{F}$. At temperature above that level, many of the additive used with a water-based fluid can break down.

\subsection{Production}

For the oil or gas to be generated, a pressure gradient must be established in the formation on the pore level. This pressure gradient then forces oil from one pore to the next, and ultimately to the production well. There are two basic ways for such a pressure gradient to be established. First is to have a production well with a lower pressure than that of the surrounding formation. This will cause oil to flow to the well, where it can be produced. Second is to increase the pressure in some parts of the formation by injecting fluids. This will force oil to flow away from the injection wells to lower pressure production wells. In many reservoirs, a combination of low pressure at the production well coupled with high pressure at an injection well are used. The production of oil and gas generates a variety of wastes. The largest waste stream is produced water, with its associated constituents.

\subsubsection{Produced Water}

The largest volume waste stream in the upstream problem industry is produced water. For mature oil fields, the volume of produced water can be several orders of magnitude greater than volume of produced oil. The environmental impact of produced waters arises from its chemical composition. Produced water contains dissolved solids and hydrocarbons. Table 2 shows heavy metal concentration in produced water.

Most produced water contains a variety of dissolved solids. The most common dissolved solid is salt (sodium chloride). Salt concentration in produced water range between a few parts per thousand to hundreds of parts per thousand (ppt). For comparison sea water contains 35 parts per thousand. In addition to salt, many produced waters also contain high levels of calcium, magnesium and potassium.

Produced water normally contains dissolved and suspended droplets of hydrocarbons and other organic molecules that are not removed by separations equipment. Hydrocarbon effluent concentrations vary widely with equipment used. The concentrations of dissolved hydrocarbons in produced water depends on solubility of hydrocarbon.

Table 2: Heavy Metal Concentrations in Produced Water

\begin{tabular}{|c|c|c|}
\hline Metal & $\begin{array}{c}\text { Average } \\
\text { Concentration } \\
\text { (microgram/L) }\end{array}$ & $\begin{array}{c}\text { Standard Deviation } \\
\text { (microgram/L) }\end{array}$ \\
\hline Cadmium & 27 & 12 \\
\hline Chromium & 186 & 68 \\
\hline Copper & 104 & 180 \\
\hline Lead & 315 & 670 \\
\hline Nickel & 192 & 307 \\
\hline Silver & 63 & 17 \\
\hline Zinc & 170 & 253 \\
\hline
\end{tabular}

Source: From Stephenson, 1992 


\subsubsection{Natural Gas Production}

As a natural gas flows from the ground, it contains a variety of impurities that must be removed before it can be sold. These impurities are primarily water vapor, carbon dioxide and hydrogen sulfide. The process of removing hydrogen sulfide and carbon dioxide is called sweetening.

Natural gas also contains fluids like propane, butane and ethane which can be separated from the gas by liquefaction. These natural gas liquids are more valuable and can be sold at higher prices.

\section{WELL STIMULATION}

The oil and gas production rate of many wells is restricted by a low permeability around the wellbore. To increase the production rate, the permeability is often increased by stimulation. The two most common form of stimulation are acidizing and hydraulic fracturing.

\section{$4.1 \quad$ Acidizing}

Acids are used to dissolved acid-soluble materials around the wellbore to increase the formation's permeability. These acid-soluble materials can include formation rocks and clays, as well as any materials added during drilling. A variety of inorganic and organic acids can be used, depending on formation. These acids include hydrochloric, formic, acetic and hydrofluoric. Additive are also required to optimize the process.

The most widely used acid is hydrochloric acid. Its main application is in low permeability carbonate reservoir. The major reaction products produced during acidizing are carbon dioxide, calcium chloride and water.

\subsection{Hydraulic Fracturing}

Hydraulic fracturing increases the permeability around a wellbore by creating a high permeability channel from the wellbore into the formation. During hydraulic fracturing, fluids are injected at a rate high enough so that the fluid pressure in the wellbore exceeds at tensile strength of the formation, rupturing the rock. The most commonly used base fluid for hydraulic fracturing is water. Water is inexpensive and inflammable. Various hydrocarbons can also be used as a base fluid. Acid is also occasionally used when a combination of acidizing and hydraulic fracturing is desired. Liquefied gases, such as carbon dioxide or liquefied petroleum gases, can also be used, particularly to fracture gas wells.

\section{HYDROCARBONS}

Crude oil contains thousands of different types of hydrocarbon molecules. The toxicities and potential environmental impacts of the different molecules vary considerably. Numerous studies have been conducted on the environmental impact of hydrocarbon exposure. In this part, the major families of hydrocarbon are discussed.

\subsection{Hydrocarbons Families}

Crude oil contains thousands of different kinds of hydrocarbon molecules, making it very difficult to characterize. Crude oil can also contain significant quantities of other elements, like sulfur, nitrogen, oxygen and heavy metals, further complicating its characterization. Crude oil is typically composed of between $50 \%$ and $98 \%$ hydrocarbon. Other important components can be sulfur $(0-10 \%)$, nitrogen $(0-1 \%)$ and oxygen $(0-5 \%)$. Heavy metal can be found in the parts-per-million level [10].

The molecules in crude oil, however, can be grouped into a few families having similar properties. These families are distinguished primarily by how the carbon atoms bond to each other and by the presence of elements other than carbon and hydrogen. Table 3 summarize most of the families of hydrocarbons found in crude oil.

Table 3: Families of Hydrocarbons

\begin{tabular}{|c|c|}
\hline Family Name & Example \\
\hline Alkanes & Methane \\
& Ethane \\
& Propane \\
\hline Alkenes(olefins) & Methane \\
& Propene \\
\hline Alkynes(acetylenes) & Ethyne \\
& Propyne \\
\hline Cyclic Alkanes (naphthenes, & Cyclopropane \\
cycloparaffins) & Cyclobutane \\
\hline Aromatics & Benzene \\
& Toluene \\
\hline
\end{tabular}

\subsection{Impact of Crude Oil on Marine Animal}

The actual impact of hydrocarbon exposure on marine animals is more complex than simple bioassay tests reveal. Oil at sublethal concentrations can significantly alter the behavior and development of marine organisms. These effects, however, are difficult to quantify. The problem of determining sublethal toxicity is further compounded because different species have different reactions and there is mixed effect when multiple toxins are present. Although there is tremendous amount of scatter in the data, most threshold concentrations of crude oil in water for effects to be observed for eggs, embryos and larvae of marine fish are between 0.01 and $5 \mathrm{mg} / \mathrm{l})[10]$.

\subsection{Impact of Crude Oil on Ecosystems}

Only a few studies have been conducted on chronic effects of hydrocarbon releases on ecosystems. No apparent long-term impacts on productivity of ecosystems have been observed. In all cases, the affected areas recovered after the hydrocarbon source had been removed, although full recovery could take a number of years. One difficulty with ecosystems studies, however, is that little is known about ecosystems that have not been exposed to hydrocarbons. This makes it difficult to determine what lasting effects hydrocarbons do have on ecosystems [10].

\subsection{Impact on Human Health}

The impact of hydrocarbons on human health depends somewhat on whether exposure was from ingestion, inhalation or dermal (skin) contact and on whether the exposure was acute (short-term) or chronic (longterm) .

The acute effects of ingestion may include irritation on the mouth, throat and stomach and digestive disorders and/or damage. Small amounts of hydrocarbons can be drowning into the lungs, either from swallowing or vomiting and may cause respiratory impact such as pulmonary edema or bronchopneumonia.

The chronic effect of ingestion may include kidney, liver or gastrointestinal tract damage or abnormal heart rhythms. Prolonged and/or repeated exposure to aromatics like benzene may cause damage to the bloodproducing system and serious blood disorders including leukemia. The metabolism of aromatic hydrocarbons after ingestion can result in the creation of mutagenic or carcinogenic derivative, even if the original hydrocarbon is relatively nontoxic [10].

\subsection{Impact on Plant Growth}

Hydrocarbons also impact plant growth when released on land. Levels of oil and grease above a few percent in soils (by weight) have shown degradation of plant growth. Levels below of few percent have shown an actual enhancement of some crop growth. Recovery of an exposed site after a one-time hydrocarbon release usually occurs after a few months [11]. A level of $1 \%$ oil and grease is recommended as a practical threshold where the hydrocarbons become detrimental to plant life [12]

Airborne hydrocarbons emitted during blowouts can also impact plant growth around the wellhead. Long-term growth rate reductions have been observed in coniferous forest growth following blowout at distances as great as $2 \mathrm{~km}$ from the wellhead [13]

\section{ENVIRONMENTAL TRANSPORTATION OF PETROLEUM WASTES}

The environmental impact of most release of petroleum industry wastes would be minimal if the wastes remained at their points of release. Unfortunately, wastes can migrate away from a release point by a number of pathways. These pathways include transport along the surface of the earth or along the surface of a body of water and transport through the air.

\section{PLANNING FOR ENVIRONMENTAL PROTECTION}

Many operations in the petroleum exploration and production industry have the potential to impact the environment in some way. Because of high costs of noncompliance with numerous regulation governing the industry and high costs associated with the loss of public trust for damaging the environment, substantial resources must be dedicated to minimizing environmental impact. Because the industry resources are limited, comprehensive environmental protection plans, including waste management and contingency plans, are needed to optimize the use of those resources. 


\subsection{Waste Management Plans}

Waste management plans identify exactly how each waste stream should be managed. They ensure that appropriate engineering controls, proper waste management options, adequate recordkeeping and reporting systems and ongoing employee training are in place. The information obtained from environmental audits can be used in developing a waste management plan.

One of the first steps in developing a waste management plan is to identify the region and scope to be covered. All materials generated within the region must be identified, quantified and characterized. These data must include chemical toxicological, health, fire, explosive and reactivity information. They should also include first aid procedure to be used in the event of human exposure to the material.

\subsection{Waste Management Actions}

A number of examples of waste management activities for drilling and production operations according to the hierarchy of waste management listed as follow:

- Waste minimization

- Improved operations

- Material substitution

- Equipment modifications

\subsection{Material Reuse}

Many of the materials in drilling and production waste streams can be used more than once. If materials are intended for future use, they are not wastes. The following materials have a potential for reuse: acids, amines, metals, oils, plastics, antifreeze, batteries, solvent. Material reuse can be facilitated by installing equipment that allows reuse. For example, closedlooped systems can be installed so that solvent and other materials can be collected and reused in plant processes.

\subsection{Employee Training}

For any environmental protection plan to be effective, it must be understood and accepted by those who must implement it. Best results are normally obtained by establishing a formal training program for all employees who make decision that can impact the environment. Once developed, environmental protection plans will serve as handy guides for all the people to use in making the best decisions regarding wastes. A critical step in the effective implementation of the environmental protection plan is to identify the people involved with the actual decision impacting the environment and to effectively communicate the plan to them. Employees need easy access to information on approved methods for handling, treating and disposing of different waste streams as well as applicable regulations.

\section{WASTE TREATMENT METHODS}

During drilling and production activities, many wastes are generated that must be treated. The purpose of waste treatment is to lower the potential hazards associated with a waste by reducing its toxicity, minimizing its volume, and/or altering its state so that it is suitable for a particular disposal option. For many wastes, treatment is required prior to final disposal. A variety of treatment methods are available for most wastes, but not all methods can be used on all waste streams. The different treatment methods vary considerable in effectiveness and cost.

Most waste treatment processes involve separating a waste stream into its individual components for example, removing dissolved or suspended hydrocarbons and solids from water or removing hydrocarbons from solids. In many cases, a series of methods may be needed to obtain the desired treatment levels [14].

\subsection{Treatment of Water}

A number of methods are available to treat contaminated water to prepare it for reuse or disposal. The contaminants in water most commonly encountered in the petroleum industry can be grouped into two broad categories: Hydrocarbons and solids. These contaminants can be either suspended or dissolved.

\subsubsection{Removal of Suspended Hydrocarbons Methods}

- Gravity separation

- Heater treatment

- Gas flotation

- Filtration
- $\quad$ Electric field separation

- Biological process

8.1.2

\section{Removal of Dissolved Hydrocarbons Methods}

- Adsorption

- Volatilization

- Biological Processes

- Precipitation

- Ultraviolet Irradiation

- Oxidation

8.1.3 Removal of Suspended Solids Methods

- Gravity separation

- Filtration

- Coagulation

8.1.4

\section{Removal of Dissolved Solids Methods}

- Ion exchange

- Precipitation

- Reverse Osmosis

- Evaporation/Distillation

- Biological process

8.2

\section{Treatment of Solid}

During drilling and production activities, a substantial volume of contaminated cutting, soil and produced solids are generated. The most common treatment method is to separate the solids from any contaminating water and/or hydrocarbons.

8.2.1

\section{Removal of Water Methods}

- Evaporation

- Percolation

- Mechanical

\subsubsection{Removal of Hydrocarbons}

- Washing

- Adsorption

- Heating

- Distillation

- Incineration

- Solvent extraction

- Biological Processes

- Filtration

\section{REMEDIATION OF CONTAMINATED SITES}

An important process in the cleanup of contaminated sites is to assess their potential to impact human health and the environment before remediation begins. A site assessment is the first step in determining what remediation method is to be used, if any. Site assessment are normally conducted in stages [15]. The first stage is to gather all relevant background information about the site. This includes reviewing available records and reports and may include interviewing site personnel. From this information, the magnitude and composition of release is to estimate. The next stage is to characterize the site. The purpose of site characterization is to determine the exact locations, contaminant concentrations and extent contaminated zone and to evaluate the potential for contaminants to migrate from the site. Depending on the magnitude of the release and its potential for adverse environmental impact, a risk assessment study may be needed. A risk assessment study would quantify the potential environmental impact of the various remediation processes being considered, and the results could be used when negotiating the specific details of a site remediation project with applicable regulatory agencies.

\section{CONCLUSION}

Many operations in the petroleum exploration and production industry 
have the potential to impact the environment in some way. One of the first steps in developing environmental protection plans is to conducts an environmental audit to identify all of the waste streams at a particular site and to determine whether those waste streams are being handled in compliance with all applicable regulations. Several benefits of environmental audits and waste management plans are that they:

- Minimize environmental damage from operations

- Minimize operating costs through saving in raw materials and production costs

- Minimize personnel costs associated with waste management by having a written plan available

- Minimize cost of treating and disposing of wastes

- Minimize employee exposure to potentially hazardous materials

\section{REFERENCES}

[1] John C. Reis 1996. Environmental Control in Petroleum Engineering, Golf publishing company.

[2] American Petroleum Institute. 1987. Oil and Gas Industry Exploration and Production Wastes. API Publishing, 471-01-09, Washington, D.C.

[3] American Petroleum Institute. 1989. API Environmental Guidance Document: Onshore Solid Waste Management in Exploration and Production Operations, Washington, D.C.

[4] American Petroleum Institute. 1979. No Emission from Petroleum Industry Operations. API Publication, 4311, Washington, D.C.

[5] American Petroleum Institute. 1980. Fugitive Hydrocarbon Emissions from Petroleum Production Operations: Volume I and II," API publication 4322, Washington, D.C.
[6] American Petroleum Institute. 1978. Fate and Effects of Polynuclear Aromatic Hydrocarbons in the Aquatic Environment. API Publication, 4297, Washington, D.C.

[7] American Petroleum Institute. 1983. Summary and Analysis of API Onshore Drilling Mud and Produced Water Environmental Studies. API Bulletin, D19, Washington, D.C.

[8] Benoit, J.R., and Shuh, M. G., 1993. Waste Minimization at Sour Gas Facilities. Paper SPE 26011 presented at Society of Petroleum Engineers/Environmental protection Agency's Exploration and Production Environmental Conference, San Antonio, TX, March 7-10.

[9] Canadian Petroleum Association. 1990. Production Waste Management Handbook for the Alberta Petroleum Industry.

[10] American Petroleum Institute. 1986a. Bacterial Activity in Ground Waters Containing Petroleum Products. API Publication, 4211, Washington, D.C.

[11] American Petroleum Institute. 1985. Surface Chemical Aspects of Oil Spill Sedimentation. API Publication, 4380, Washington D.C.

[12] American Petroleum Institute. 1986. The Role of Chemical Dispersants in Oil Spill Control. API Publication, 4425, Washington, D.C.

[13] American Petroleum Institute. 1987. Effects of a Dispersed and Undispersed Crude Oil Mangroves, Seagrasses and Corals. API Publication, 4460, Washington, D.C.

[14] Gerischer, H. and Heller, A. 1991. The Role of Oxygen in Photooxidation of Organic Molecules on Semiconductor Particles. The Journal of Physical Chemistry, 95 (13), 5261-5267.

[15] Jordan, R. E. and Payne, J. R. 1980. Fate and Weathering of Petroleum Spilled in Marine Environment: A Literature Review and Synopsis, Ann Arbor Science Publisher, Ann Arbor , MI 